\title{
Calculus Application to Topographic Mapping
}

Veronica Zapata

University of South Florida

\author{
Advisors: \\ Arcadii Grinshpan, Mathematics and Statistics \\ Julio Rodriguez, CEO at Global Projects Surveying LLC \\ Problem Suggested By: Wilnelia Badillo
}

Field of Study for Problem Suggester: Global Projects Surveying LLC

Follow this and additional works at: https://digitalcommons.usf.edu/ujmm

Part of the Mathematics Commons

UJMM is an open access journal, free to authors and readers, and relies on your support:

Donate Now

\section{Recommended Citation}

Zapata, Veronica (2019) "Calculus Application to Topographic Mapping," Undergraduate Journal of Mathematical Modeling: One + Two: Vol. 10: Iss. 1, Article 3.

DOI: https://doi.org/10.5038/2326-3652.10.1.4908

Available at: https://digitalcommons.usf.edu/ujmm/vol10/iss $1 / 3$ 


\title{
Calculus Application to Topographic Mapping
}

\begin{abstract}
The goal of the paper is to find the volume of water in a ditch. An example image of ditch is given in Appendix $C$. The first act that before any calculation can be performed is to record the field work. Once at the property the ditch must be identified. Three points of elevations per section should be measured by the surveyor; one point is at the center of the ditch (the lowest point) and the two ones are at the ends (the highest points). The sections are detailed in Appendix A. Using the elevation points from the property, we can define a model function and then approximate the corresponding cross-sectional area and the required volume. We are omitting any pipelines or drainage of the ditch.
\end{abstract}

\section{Keywords}

area, volume, Cavalieri's Principle, ditch

\section{Creative Commons License}

(c) (i) ()

This work is licensed under a Creative Commons Attribution-Noncommercial-Share Alike 4.0 License. 


\section{PROBLEM STATEMENT}

A client at Global Projects Surveying is requesting the volume of water stored in the ditch inside their property. They live in a residential property.

\section{MATHEMATICAL DESCRIPTION AND SOLUTION APPROACH}

1. Collection of information at property

2. Development of approximate math equation

3. Validation of ditch model to field information

4. Use of Integral Calculus to find volume of water in a ditch

Field Data:

\begin{tabular}{|lrrr|}
\hline Elevations & Point 1 & Point 2 & Point 3 \\
\hline Section 1 & 32.34 & 30.28 & 32.41 \\
\hline Section 2 & 32.12 & 30.09 & 32.42 \\
\hline Section 3 & 31.91 & 29.86 & 32.09 \\
\hline Section 4 & 31.66 & 29.69 & 31.92 \\
\hline
\end{tabular}

The four sections build up a 60-foot length, where each section is 20 feet long. The three points of elevation are taken on the sides and center of the ditch corresponding to their section (shown in Appendix A). It is clear that the data brought from the field to calculate are approximate and never exact due to the low margins of error.

In order to use these elevations to form a function, we equal the values of points 2 to 0 . In order to do that, however, we must subtract the values of points 1 and 3 by the value of point 2 , according to their section.

Fixed Data:

\begin{tabular}{|lcll|}
\hline Elevations & Point 1 & Point 2 & Point 3 \\
\hline Section 1 & 2.06 & 0.00 & 2.13 \\
\hline Section 2 & 2.03 & 0.00 & 2.33 \\
\hline Section 3 & 2.05 & 0.00 & 2.23 \\
\hline Section 4 & 1.97 & 0.00 & 2.23 \\
\hline
\end{tabular}

Using these data, we can approximate our values to produce a model function:

$y=g(X)=\frac{X^{2}}{2}$.

This is an approximate function; since the data from the property are approximate so is our function as well. The function on the ditch illustrates the walls of the ditch coming together in the form of a simple parabola. You may refer to it in Appendix B:

Point 1 (-2, 2), Point $2(0,0)$, Point $3(2,2)$. 
We need the area of the region between the curve (1) on the suitable interval and the line $y=H$, where $H$ is the "height" of the ditch. A natural function for this is given by equation (2). In fact we lower the border of the parabola (1) to the value of the height of the ditch (see Illustration in Appendix D).

$f(X)=\frac{X^{2}}{2}-H$

In this case, $H=2$ feet and $f(X) \leq 0$.

We use the definite integral (3) generated by function $|f|$ to find the needed area. Its boundaries are -2 feet and 2 feet; that is approximated information from the field. We have

$$
\text { area }(|f|)=\int_{-2}^{2}\left(H-\frac{X^{2}}{2}\right) d x=2 \int_{0}^{2}\left(H-\frac{X^{2}}{2}\right) d x=2\left(H X-\frac{X^{3}}{6}\right) \quad \text { as } X=H=2 .
$$

From (3) we obtain: area $(|f|)=\frac{16}{3} \approx 5.33 f^{2}$, which turns out to be a suitable approximation of the "cross-sectional area” of the ditch.

Approximating the volume by cross-sectional area, which is $\approx$ constant along the ditch, is a straightforward step for a non-curved ditch. However it is worth mentioning that for more complicated curved ditches one can use the same approach based on Cavalieri's Principle. It states that if a family of parallel planes gives equal cross-sectional areas for two solids and $\mathrm{B}$, then the volumes of $\mathrm{A}$ and $\mathrm{B}$ are equal. 
The units of measurement in this exercise are in feet and feet squared, the negative value of $f(X)$ is only an indicator that the equation is under the line of origin. If we use the exact values of each section, the answer will approximate very much to the value of this model. Therefore, to finalize our answer we will multiply 60 feet (the length) by 5.33 feet squared.

$$
60.0 \text { foot } \times 5.33 f^{2}=319.8 f^{3}
$$

The volume of water able to be stored in our client's ditch is 319.8 feet cubed.

\section{DISCUSSION}

The objective for the client is fulfilled and the client is satisfied. The work was not easy though the method of integration was not that difficult as the author expected it to be. It took time to go to the field with a crew and see how the measurements were done as well as to figure out a good function for our problem. The calculations from then on were fairly simple.

\section{CONCLUSION}

Although our calculations only serve as a piece of information, it is key information for our clients. That is why they pay for such information. Topographic services do not always include measuring ditches; they typically only provide the elevation values. However, since we have the ability to use simple calculus applications, we are able to charge for this service. That is more work, and more revenue for the business.

\section{NOMENCLATURE}

$H=$ HEIGHT OF DITCH (USING LOWEST ELEVATION)

ALL MEASUREMENTS IN FEET, EET SQUARED, OR FEET CUBED 


\section{REFERENCES}

Stewart, J. (2012). Essential Calculus: Early Transcendentals. Mason, Ohio: Cengage Learning “Town of Truckee.” Drainage/Ditch Cleaning | Town of Truckee, www.townoftruckee.com/government/engineering-and-public-works/public-works/roadmaintenance/drainage-ditch-cleaning.

\section{APPENDIX}

A

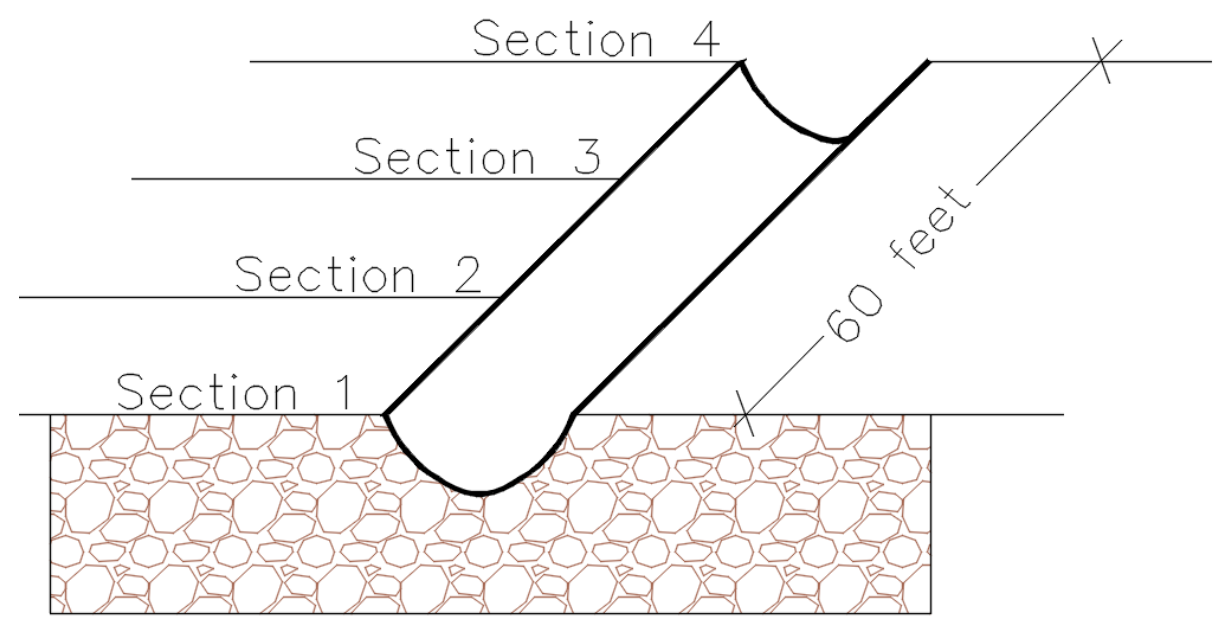

B

\section{DITCH (TYPICAL SECTON)}

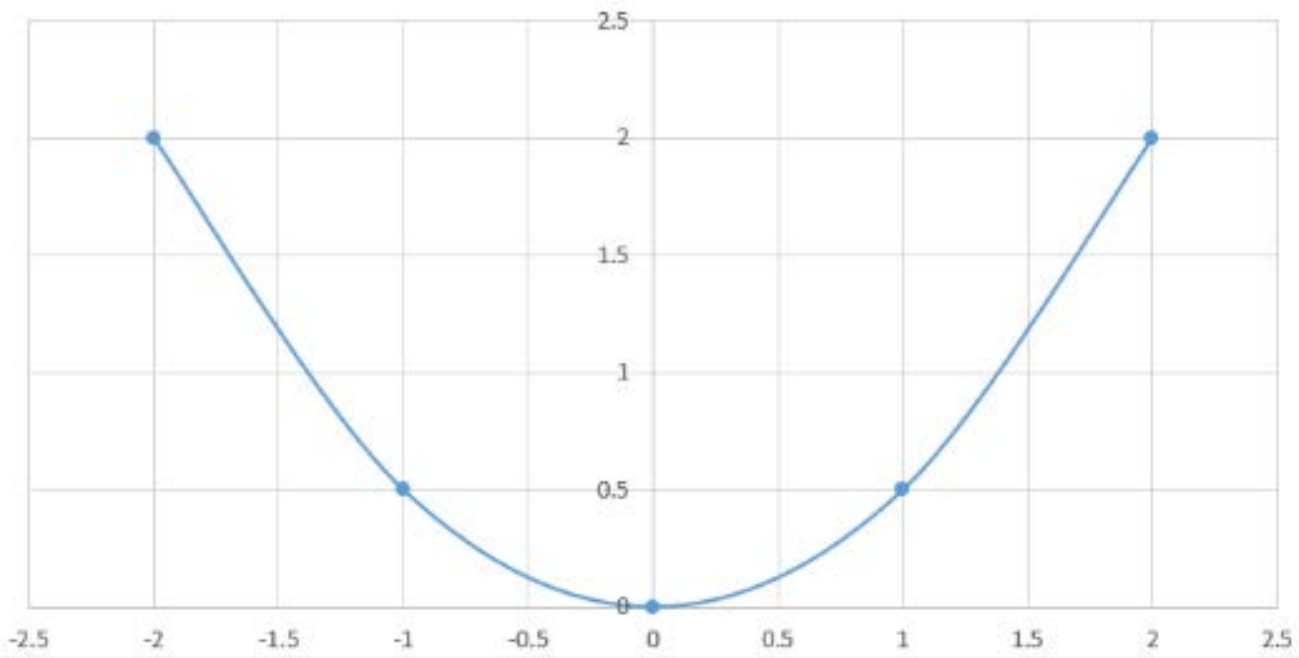


C

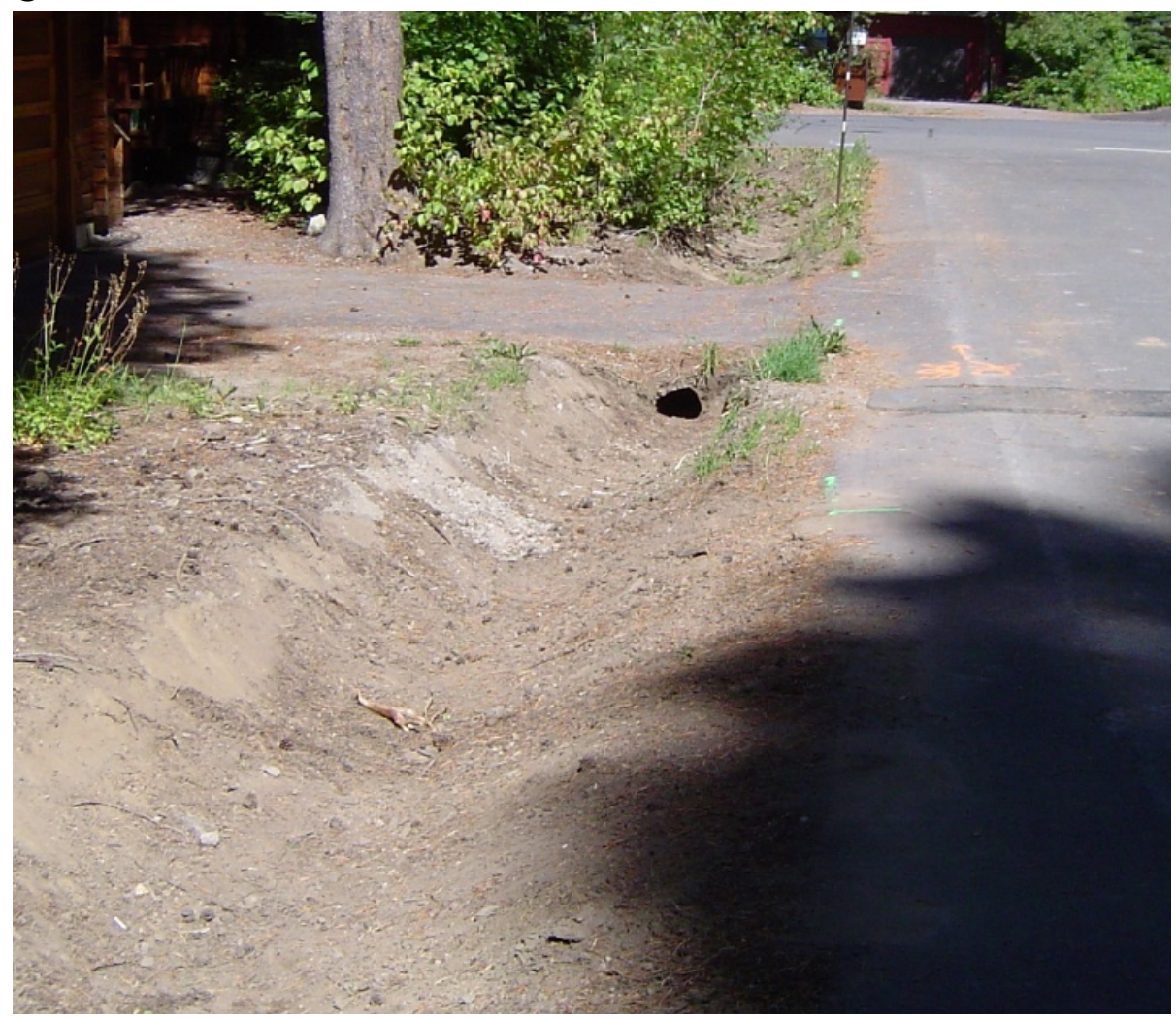

D

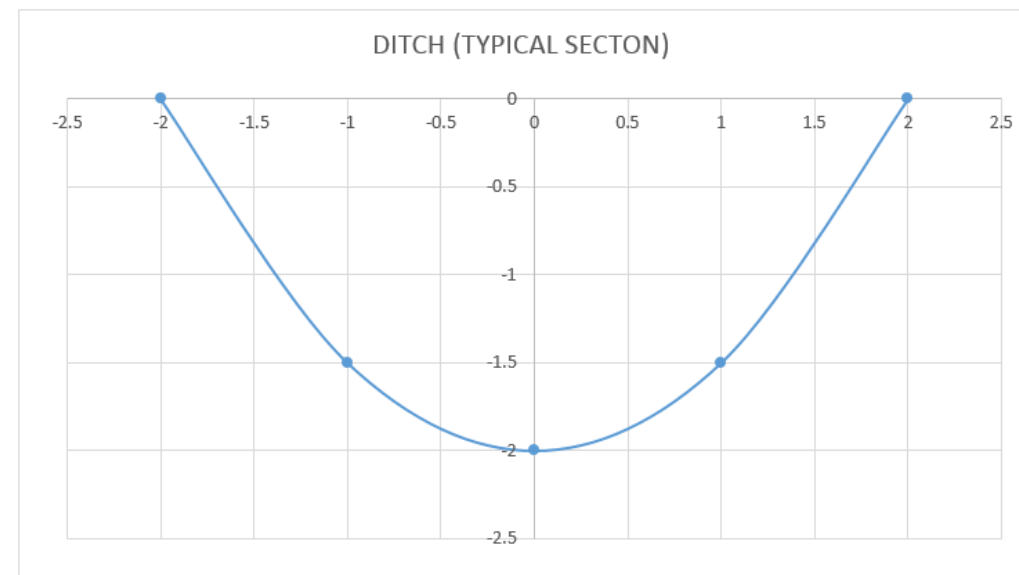

